\title{
MARCAÇÃO IMUNO-HISTOQUÍMICA DA RESPOSTA MACROFÁGICA E ASTROCITÁRIA NO TRONCO ENCEFÁLICO DE RATOS WISTAR SUBMETIDOS AO MODELO GLIOTÓXICO DO BROMETO DE ETÍDIO E TRATADOS COM CICLOFOSFAMIDA
}

\author{
Melissa Sanchez', Eduardo Fernandes Bondan', Maria Anete Lallo', \\ Idércio Luiz Sinhorini², Maria Lúcia Zaidan Dagli', Paulo Cesar Maiorka², \\ Luis Antonio Violin Dias Pereira, Dominguita Lühers Graça ${ }^{4}$
}

RESUMO - O gliotóxico brometo de etídio (BE) foi utilizado para o estudo da resposta macrofágica e astrocitária sob imunossupressão com ciclofosfamida (CY). Investigou-se a imunorreatividade astrocitária à proteína glial fibrilar ácida (GFAP) e à vimentina (VIM), e a imunorreatividade macrofágica ao ED1 após injeção do BE. Foram utilizados ratos Wistar adultos injetados na cisterna basal com salina a 0,9\% (grupo I), BE a 0,1\% (grupo II) e BE a 0,1\%, imunossuprimidos com CY (grupo III). Fragmentos do tronco encefálico foram colhidos do $1^{\circ}$ ao $21^{\circ}$ dia pós-injeção para estudo imuno-histoquímico da GFAP, VIM e ED1. Nos grupos II e III, observou-se imunorreatividade aumentada para GFAP e re-expressão de VIM. No grupo II, células ED1-positivas foram observadas a partir do $2^{\circ}$ dia e no grupo III, a partir do $3^{\circ}$ dia. Aos 14 dias pósinjeção, havia mais células ED1-positivas no grupo III. A CY aparentemente não alterou a resposta astrocitária.

PALAVRAS-CHAVE: desmielinização-remielinização, brometo de etídio, imunossupressão, ED1, GFAP, vimentina.

\begin{abstract}
Immunohistochemical staining of the macrophagic and astrocytic response in the brainstem of Wistar rats submitted to the ethidium bromide gliotoxic model and treated with cyclophosphamide

ABSTRACT - The gliotoxic ethidium bromide (EB) was used to study morphologically the macrophagic and astrocytic response under immunosuppression by cyclophosphamide (CY). Astrocyte immunoreactivity to glial fibrillary acidic protein (GFAP) and vimentin (VIM) and macrophagic immunoreactivity to ED1 were investigated after EB injection. Male Wistar rats were injected with $0.9 \%$ saline solution (group I), $0.1 \%$ $\mathrm{BE}$ (group II) and $0.1 \%$ EB associated with CY treatment (group III). Brainstem samples were collected from the $1^{\text {st }}$ to the $21^{\text {st }}$ day post-injection for GFAP, VIM and ED1 immunostaining. In groups II and III, it was observed increased immunoreactivity to GFAP and reexpression of VIM. In group II, ED1-positive cells were noted after the $2^{\text {nd }}$ day and in group III, after the $3^{\text {rd }}$ day. On the $14^{\text {th }}$ day post-injection, it was observed a greater quantity of ED1- positive cells in group III than in group II. Apparently, CY did not change the astrocytic response pattern.
\end{abstract}

KEY WORDS: demyelination-remyelination, ethidium bromide, immunosuppression, ED1, GFAP, vimentin.

Mielina é estrutura membranosa característica do tecido nervoso, depositada em segmentos ao longo de fibras nervosas selecionadas e que funciona como isolante a fim de aumentar a velocidade de transmissão do estímulo entre o corpo celular neuronal e seu $a^{1} o^{1,2}$. A ocorrência de desmielinização é observada em muitas doenças de ocorrência espontânea no homem e em outros animais ${ }^{3}$. O brometo de etídio (BE) tem sido usado como droga indutora de desmielinização primária no sistema nervoso central (SNC) ${ }^{4}$ e

\footnotetext{
1Universidade Paulista, São Paulo SP, Brasil; ${ }^{2}$ Departamento de Patologia, Faculdade de Medicina Veterinária e Zootecnia, Universidade de São Paulo (USP), São Paulo SP, Brasil; ${ }^{3}$ Departamento de Histologia e Embriologia, Universidade Estadual de Campinas (UNICAMP), Campinas SP, Brasil; ${ }^{4}$ Departamento de Patologia, Universidade Federal de Santa Maria (UFSM), Santa Maria RS, Brasil. Financiado pela Fundação de Amparo à Pesquisa do Estado de São Paulo - FAPESP.
}

Recebido 24 Novembro 2005, recebido na forma final 2 Maio 2006. Aceito 10 Junho 2006.

Dra. Melissa Sanchez - Rua Xingu 823 / 102 / Bloco 02 - 09060-050 Santo André SP - Brasil. E-mail: melissanchez@uol.com.br 
no sistema nervoso periférico (SNP) ${ }^{5}$ por destruir seletivamente as células gliais. Dentre as células gliais presentes no SNC dos mamíferos, os astrócitos constituem as maiores e mais numerosas delas, excedendo o número de neurônios na proporção de 10:16. Uma das mais notáveis características dos astrócitos é a sua vigorosa resposta a diversos tipos de agentes agressores $^{7,8}$. A resposta astrocitária inclui o aumento de seu número (astrocitose) e de suas dimensões (astrogliose). Para tal, os astrócitos sofrem transformações celulares e bioquímicas com conseqüente aumento da intensidade de marcação da proteína glial fibrilar ácida (GFAP) e recuperação da capacidade de expressar a vimentina (VIM) perdida durante o desenvolvimento normal do tecido9-11. Já as células microgliais pertencem ao sistema mononuclear fagocitário e podem apresentar três aspectos distintos no cérebro adulto - micróglia em repouso ou ramificada, presente no SNC livre de processos patológicos; ativada ou reativa, com ramificações citoplasmáticas mais espessas e evidentes, encontrada em processos patológicos e não-fagocítica; e finalmente, fagocítica ou amebóide, caracterizada por uma forma mais arredondada ${ }^{12}$. Um anticorpo amplamente utilizado para avaliar a resposta macrofágica/microglial é o anticorpo monoclonal denominado de ED $1^{13}$. O antígeno reconhecido pelo anticorpo monoclonal ED1 é expresso nas membranas dos grânulos citoplasmáticos como os fagolisossomos e a quantidade de antígeno expresso parece estar relacionada à atividade fagocítica do respectivo tipo celular ${ }^{14}$.

Embora a ativação da micróglia possua um papel benéfico na defesa do hospedeiro mediada pelo sistema imune, os mediadores inflamatórios liberados por essas células têm sido associados a processos neurodegenerativos ${ }^{15}$. Quando ocorre lesão no SNC, os fagócitos mononucleares reativos migram ao sítio de injúria e fagocitam os debris antes de liberarem os fatores citotóxicos. A supressão dos eventos celulares iniciais através de fármacos que modulem a resposta inflamatória pode ser utilizada para prevenir o dano tecidual subseqüente à resposta macrofágica ${ }^{16}$.

A resposta inflamatória mostra-se severamente comprometida pelo tratamento prolongado com ciclofosfamida $(\mathrm{CY})^{17,18}$. Tal fármaco tem sido utilizado por suas propriedades imunossupressoras no tratamento de doenças auto-imunes ${ }^{19-21}$, tais como a esclerose múltipla (EM), na qual os mecanismos envolvidos na perda e reconstrução mielínica são ainda pouco compreendidos, bem como os antígeno(s)-alvo das supostas reações imunes ${ }^{22}$. Nesse sentido, o estudo das respostas astrocitária e macrofágica em animais imunocompetentes ou tratados com CY pode levar a melhor compreensão dos fenômenos celulares envolvidos no reparo do tecido nervoso em condições patológicas.

\section{MÉTODO}

Foram utilizados ratos Wistar, machos, adultos jovens (4 a 6 meses de idade). O grupo I compreendeu 6 animais, injetados na cisterna basal com $10 \mu \mathrm{L}$ de solução salina a $0,9 \%$, sendo 1 animal, para cada período, perfundido aos $1,2,3,7,14$ e 21 dias pós-cirurgia. O grupo II, por sua vez, constou de 12 animais, injetados intracisternalmente com $10 \mu \mathrm{L}$ de solução a $0,1 \%$ de BE em salina a $0,9 \%$ estéril, sendo 2 animais perfundidos para cada período aos 1, 2, 3, 7, 14 e 21 dias pós-cirurgia. No grupo III, os ratos foram tratados com CY durante todo o período da realização do experimento a partir da injeção intracisternal de $10 \mu \mathrm{L}$ de $\mathrm{BE}$ a $0,1 \%$ e foram perfundidos 2 animais, para cada período, nos dias 1, 2, 3, 7, 14 e 21 pós-cirurgia.

A indução anestésica foi realizada com éter etílico P.A. por via inalatória e mistura anestésica de 5:1 de cloridrato de quetamina e cloridrato de xilazina, respectivamente. Com auxílio de um motor de teto, de uso odontológico e de uma broca de número 2 , foi feito um orifício na calota óssea a 0,85 $\mathrm{cm}$ póstero-diagonalmente e à direita do bregma até a exposição da duramáter. Esta era aberta com a própria agulha da seringa de Hamilton utilizada para injeção de BE ou de solução salina.

Foram injetados $10 \mu \mathrm{L}$ de solução de BE a 0,1\% em salina a $0,9 \%$ estéril na cisterna basal dos animais dos grupos II e III, enquanto que o mesmo volume de solução salina a $0,9 \%$ foi igualmente injetado nos animais do grupo I.

Os animais pertencentes ao grupo III receberam logo após a cirurgia uma primeira dose de $50 \mathrm{mg} / \mathrm{kg}$ de CY (Genuxal ${ }^{\circledR}$ ) por via intraperitoneal e foram tratados com $\mathrm{CY}$ por todo o período do experimento mediante duas doses semanais de 50 e $30 \mathrm{mg} / \mathrm{kg}$ respectivamente, intraperitonealmente administradas com um intervalo mínimo de 72 horas entre elas.

A perfusão intracardíaca foi realizada com solução de formol a $10 \%$ em tampão fosfato de Sorensen ( $\mathrm{pH}$ neutro). Os animais foram profundamente anestesiados, utilizandose éter etílico P.A. por via inalatória e, intraperitonealmente, mistura anestésica de 5:1 de cloridrato de quetamina e cloridrato de xilazina, respectivamente. Os animais foram perfundidos pela artéria aorta por aproximadamente 15 a 20 minutos ou até serem perfundidos $250 \mathrm{~mL}$ de solução. Após perfusão, o tronco encefálico foi removido e separado em mesencéfalo e ponte, os quais foram imersos em solução fixadora de formol a $10 \%$ em tampão fosfato de Sorensen ( $\mathrm{pH}$ neutro).

A metodologia de acesso à cisterna basal e subseqüente injeção de BE ou salina foi previamente descrita por Bondan e col. ${ }^{22}$.

As amostras permaneceram em solução fixadora por, no mínimo, 72 horas para desidratação, diafanização e inclusão em parafina. Foram selecionados alguns blocos a partir da observação das lâminas coradas por H-E. Cortes 
histológicos dos mesmos foram colhidos em lâminas silanizadas e, posteriormente, os cortes foram desparafinados. $O$ método de desmascaramento antigênico realizado para os anticorpos anti-GFAP e anti-VIM foi através de microondas; para o anticorpo anti-ED1 o método de desmascaramento antigênico utilizado foi o proteolítico através da aplicação de pronase. A peroxidase endógena foi bloqueada incubando-se as lâminas por 30 minutos em metanol contendo $30 \%$ de peróxido de hidrogênio PA.

Para a marcação imuno-histoquímica da GFAP, VIM e ED1, o método utilizado foi o da avidina-biotina segundo Hsu e colaboradores ${ }^{23}$, sendo cada etapa intercalada por lavagem das lâminas em solução salina tamponada com fosfato. Os cortes foram incubados, em câmara úmida, a $4^{\circ} \mathrm{C}$, por 16 horas, com o anticorpo primário anti-GFAP (Rabbit anti-cow GFA, code number ZO334, Dako), padronizado na diluição 1:1000, ou com o anticorpo primário anti-VIM (Mouse anti-swine VIM, code number M0725, Dako), padronizado na diluição de 1:200 ou com anticorpo primário anti-ED1 (mouse anti-rat ED1 antigen/purified, code number MCA341R , Serotec), padronizado na diluição 1:100 (consideradas as mais adequadas após prévia titulação). Posteriormente, foi realizada a incubação dos cortes por 30 minutos com anticorpo secundário biotinilado na diluição de 1:100 e, após, a aplicação por 30 minutos do conjugado estreptavidina-biotina-peroxidase (Novostain Super ABC Kit, Novocastra), diluído em solução salina tamponada com fosfato. Foi aplicada solução substrato de peroxidase (peróxido de hidrogênio a 0,02\% com diaminobenzidina a 0,1\% em salina tamponada). Finalmente, os cortes foram lavados, contracorados com hematoxilina, desidratados, diafanizados e montados com resina sintética.

O presente estudo foi aprovado pela comissão de bioética da Faculdade de Medicina Veterinária e Zootecnia da Universidade de São Paulo (FMVZ - USP).

\section{RESULTADOS}

Nos animais do grupo I (animais injetados com salina), pequenas lesões, limitadas à região da ponte e induzidas pelo traumatismo da injeção, com presença de edema, foram observadas. Observou-se preservação dos astrócitos GFAP-positivos e VIM-negativos e marcação menos intensa para GFAP em relação aos grupos II e III. Marcação para VIM não foi observada nos astrócitos centrais ou periféricos do local injetado. Houve marcação de alguns macrófagos para ED1 aos 3 e 7 dias após a injeção de BE.

No grupo II (animais injetados com BE, mas não tratados com (Y), as lesões induzidas pelo gliotóxico na cisterna basal apresentaram extensão variável ao longo do tronco encefálico, estendendo-se, em alguns animais, desde o mesencéfalo até o término da ponte, onde chegavam a comprometer de $1 / 3$ a $1 / 2$ da mesma ventralmente, em proximidade às meninges. Observou-se, 1 dia pós-injeção do $B E$, o desaparecimento dos astrócitos normais (GFAP+VIM-) do centro da lesão. Aos 2 dias pós-injeção de BE, alguns macrófagos começaram a apresentar marcação para ED1 na área central da lesão.

Aos 3 dias, visualizaram-se células GFAP-positivas e VIM-positivas dotadas de prolongamentos espessados nas bordas da área lesada, e grande quantidade de macrófagos marcados pelo anticorpo anti-ED1 no centro lesional. Aos 7 dias pós-injeção, observaramse áreas de aspecto pseudocavitário com aumento do espaço extracelular, intensa imunorreatividade para GFAP e presença de grande número de células VIM-positivas no sítio lesional (Figs 1 e 2). Houve marcação de grande número de macrófagos na área de lesão através do anticorpo anti-ED1 .

Aos 14 dias, foi encontrada melhor organização do tecido, porém mantendo a presença de edema e o aumento do espaço extracelular na região da lesão, com presença de numerosas células ED1-positivas.

Apesar do relativo desaparecimento central de células marcadas para GFAP, foi observado, nas bordas da área lesada e ao longo do trajeto da agulha, vigorosa reação astrocitária, evidenciada por prolongamentos celulares espessados fortemente marcados para GFAP e VIM. Enquanto o aumento da marcação para GFAP ocorreu em astrócitos mais distantes das bordas da lesão, a imunorreatividade para VIM foi expressa apenas nas margens imediatas da área de injúria induzida pelo gliotóxico.

Já aos 21 dias, observou-se grande quantidade de macrófagos marcados para ED1, porém em número aparentemente menor que o encontrado aos 3 e 7 dias pós-injeção de BE. Nos diferentes períodos avaliados, foram encontrados pequenos focos hemorrágicos resultantes do traumatismo da injeção.

Nos animais do grupo III (injetados com BE e tratados com (Y), a extensão, bem como a aparência histológica das lesões induzidas foram semelhantes àquelas observadas no grupo II. Em relação à marcação imuno-histoquímica para GFAP e VIM, não houve qualquer diferença aparente neste grupo em relação ao grupo II. Quanto à marcação imuno-histoquímica para ED1, não foi possível a observação de macrófagos marcados para o mesmo até o terceiro dia pósinjeção de BE.

Aos 3 dias, no entanto, embora já fosse observada a presença de células ED1-positivas na área de lesão, podia-se constatar que o número das mesmas era bastante inferior àquele encontrado no mesmo período do grupo II.

No $7^{\circ}$ dia, a presença de macrófagos marcados para ED1, apesar de maior em relação ao $3^{\circ} \mathrm{dia}$, ainda se apresentava inferior à encontrada no grupo II. Aos 


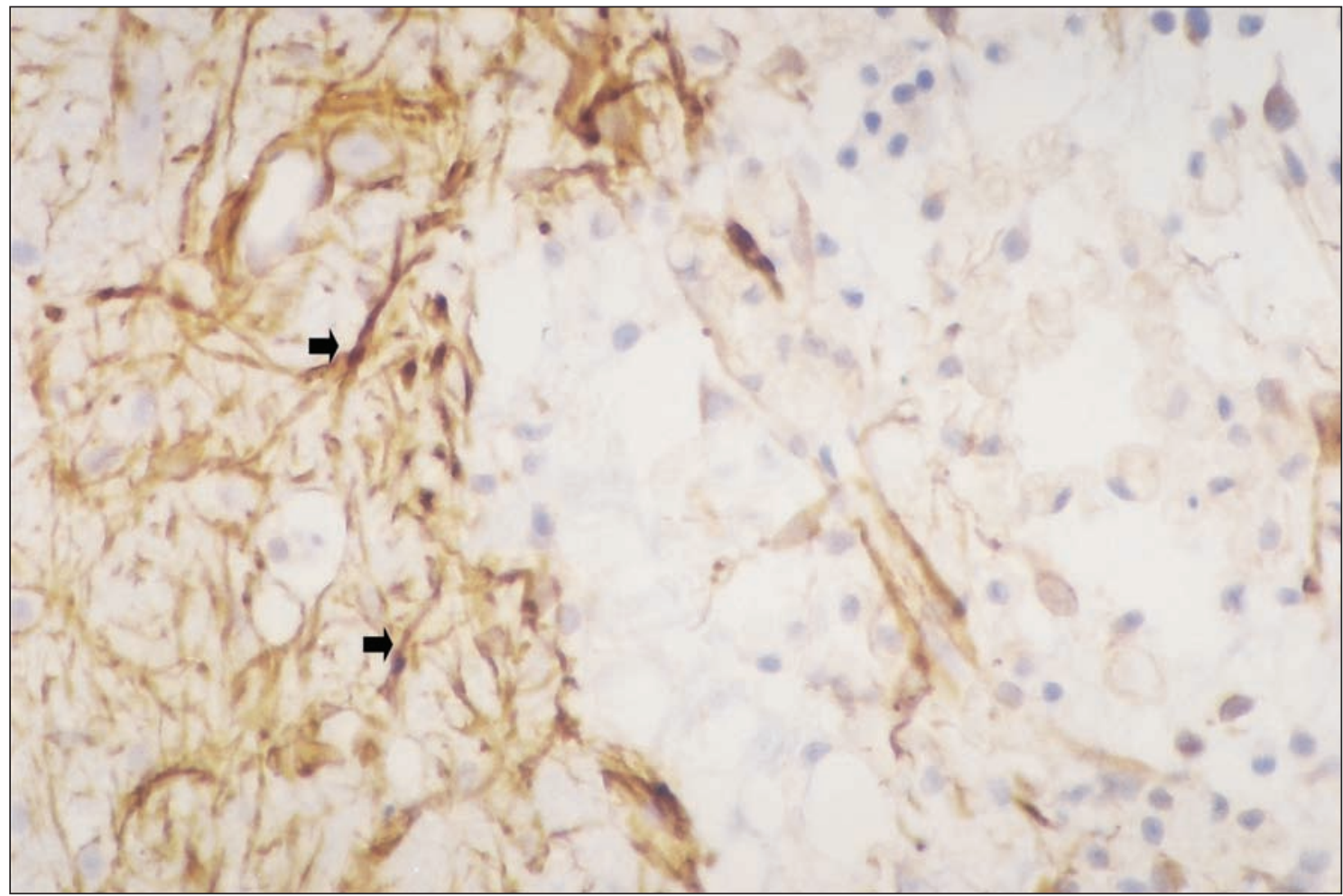

Fig 1. Astrócitos fortemente marcados para GFAP em área de periferia da lesão 7 dias pós-injeção de BE em animais imunocompetentes. Observam-se os prolongamentos astrocitários espessados. Grupo II. Obj. 400x.

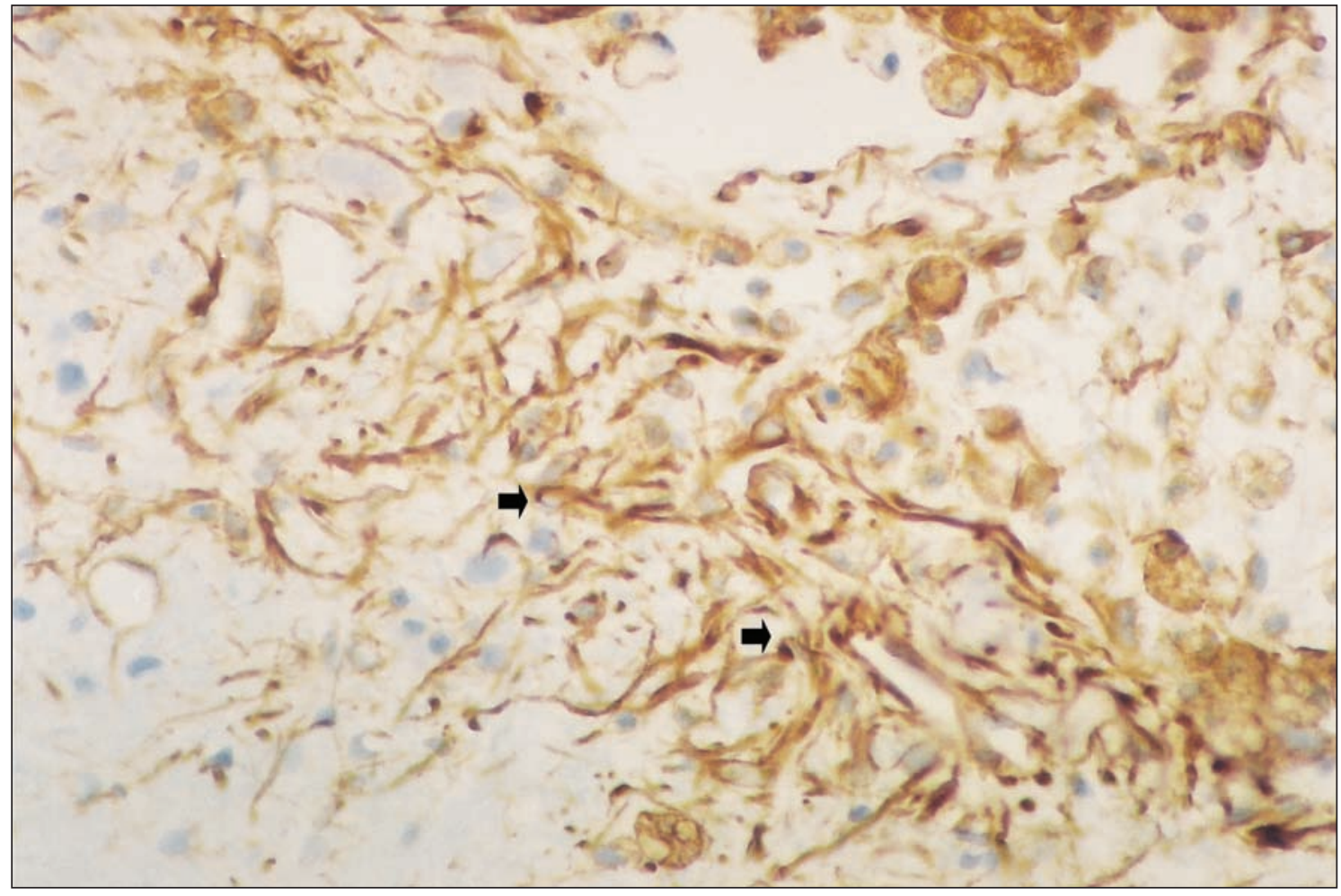

Fig 2. Astrócitos fortemente marcados para VIM em área de periferia da lesão 7 dias pós-injeção de BE em animais imunocompetentes. Observa-se re-expressão de VIM nos astrócitos e prolongamentos espessados. Grupo II. Obj. 400x. 


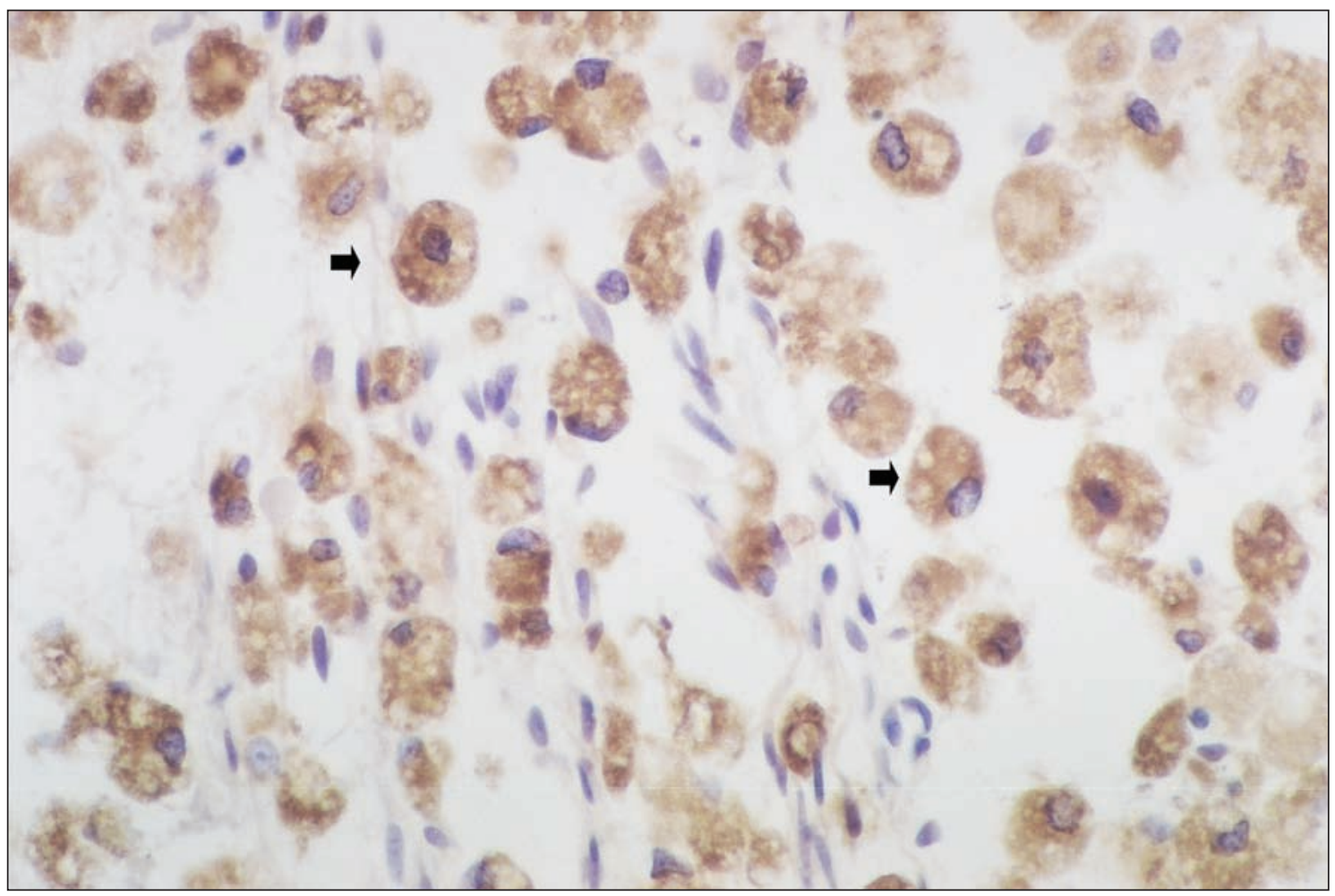

Fig 3. Macrófagos marcados pelo anticorpo anti-ED1 em área central de lesão, 14 dias pós-injeção de BE em animal imunossuprimido com ciclofosfamida. Grupo III. Obj. 400x.

14 dias, porém, o número de células ED1-positivas ultrapassou aquele observado nas lesões dos animais imunocompetentes (Fig 3). Finalmente, aos 21 dias pós-injeção do $\mathrm{BE}$, o número de células ED1-positivas voltou a diminuir tornando-se menor que o encontrado no grupo II.

O número de células encontradas nas lâminas marcadas para ED1 em aumento de 100x consta da Tabela. Os espaços assinalados com um traço são de lâminas referentes a períodos em que não se visualizaram células ED1-positivas. A Tabela considera somente as lâminas de animais nos quais se encontrou a lesão pelo BE. Por esse motivo, observa-se número menor de animais em relação aos que foram submetidos ao processo cirúrgico de injeção do gliotóxico. A contagem de células ED1-positivas nas lâminas dos animais do grupo I (injetados com solução salina a 0,9\%) não é apresentada, pois a resposta macrofágica observada foi eventual e atribuída apenas ao trauma da injeção. Foi realizada análise estatística dos resultados da Tabela empregando-se o teste $t$ de Student para medir a significância das diferenças entre as médias dos grupos. A significância estatística foi aceita em $\alpha \leq 0,05$.

Tabela. Número de células ED1-positivas observadas nos animais dos grupos II (animais imunocompetentes) e III (animais imunossuprimidos com $(Y)$ nos períodos de 1, 2, 3, 7, 14 e 21 dias pós-injeção de $B E$.

\begin{tabular}{|c|c|c|c|c|c|c|c|c|c|c|c|c|}
\hline \multirow[b]{3}{*}{ Grupo } & \multicolumn{12}{|c|}{ Número de células ED1-positivas por período } \\
\hline & \multicolumn{2}{|c|}{$1 \mathrm{dia}$} & \multicolumn{2}{|c|}{2 dias } & \multicolumn{2}{|c|}{3 dias } & \multicolumn{2}{|c|}{7 dias } & \multicolumn{2}{|c|}{14 dias } & \multicolumn{2}{|c|}{21 dias } \\
\hline & II & III & II & III & II & III & II & III & II & III & II & III \\
\hline Animal 1 & - & - & 96 & - & 338 & 61 & 216 & 158 & 130 & 141 & 112 & 101 \\
\hline Animal 2 & - & - & 90 & - & 330 & 65 & 234 & 172 & 125 & 225 & 159 & 112 \\
\hline $\begin{array}{l}\text { Média } \pm \\
\text { desvio-padrão }\end{array}$ & & & $93 \pm 4,2$ & & $334 \pm 5,7$ & $63 \pm 2,8^{*}$ & $225 \pm 12,7$ & $165 \pm 9,9 *$ & $127,5 \pm 3,5$ & $183 \pm 59,4$ * & $135,5 \pm 33,2$ & $106,5 \pm 7,8^{*}$ \\
\hline
\end{tabular}

*p $\leq 0,05$ para o grupo III comparado com o grupo II, conforme calculado pelo teste t de Student. 


\section{DISCUSSÃO}

A resposta astrocitária pode ser de 2 tipos, de acordo com o tipo de dano provocado: isomórfica, na qual os processos astrocitários apresentam-se orientados pelos elementos teciduais preservados e o arranjo dos feixes de filamentos gliais é uniforme e paralelo; anisomórfica, na qual sua disposição é irregular ao redor de lesão geralmente causadora de dano morfológico grosseiro, com ruptura da barreira hematoencefálica ${ }^{9,24}$. Em função da ação gliotóxica seletiva do BE sobre as células gliais, poupando os axônios presentes e a arquitetura vascular básica do local, o padrão reativo isomórfico foi preponderante em relação ao anisomórfico, que se limitou às regiões referentes ao trajeto da agulha no sentido dorsoventral ${ }^{22,25}$. Fernaud-Espinosa e col. ${ }^{24}$ observaram que na gliose isomórfica, as células ED1-positivas aumentavam em número gradualmente durante as duas primeiras semanas pós-lesão, diminuindo lentamente durante as 2 semanas seguintes.

No presente estudo, a evolução das lesões foi parecida com a descrita por Fernaud-Espinosa e col. ${ }^{24}$. Observou-se aumento do número de células ED1-positivas do terceiro até o sétimo dia pós-lesão nos imunocompetentes e diminuição do número das mesmas a partir do $14^{\circ}$ dia pós-lesão.

Também foi encontrada nos astrócitos reativos a reexpressão da VIM perdida durante o desenvolvimento normal do SNC. É sabido que a VIM é expressa mais precocemente que a GFAP durante o desenvolvimento embrionário do SNC, porém, durante a segunda e a terceira semana de vida extra-uterina, tende a ocorrer a transição da expressão de VIM isolada para a de GFAP como principal componente dos filamentos intermediários ${ }^{26,27}$.

Observou-se nos animais do estudo que o aumento da marcação de GFAP atingiu astrócitos distantes das bordas da lesão. Quanto à expressão de VIM, notou-se que a mesma só incluía os astrócitos imediatamente próximos à área atingida pelo gliotóxico.

Na presente investigação, embora as células ED1positivas tenham sido observadas a partir do segundo dia pós-lesão, a resposta macrofágica verificada através da contagem de tais células foi maior aos 3 e 7 dias após injeção de BE, condizendo com as observações de Fujita e col. ${ }^{28}$. Observou-se também, aos14 e 21 dias, número de células menor em relação aos 3 - 7 dias, o que também confirma os achados de Fujita e col. ${ }^{28}$.

Nos animais submetidos ao modelo gliotóxico do $\mathrm{BE}$ e imunossuprimidos com CY, observaram-se células
ED1-positivas a partir do terceiro dia pós-injeção, e o número das mesmas era inferior ao encontrado nos animais imunocompetentes no mesmo período de observação. Por outro lado, aos 14 dias pós-lesão, observou-se número significativamente maior de macrófagos no local em relação ao mesmo período no grupo de animais imunocompetentes (Fig 3).

Esses achados se aproximam das observações de Bondan e col.22, que observaram, em estudos de microscopia eletrônica de transmissão, grandes quantidades de membranas derivadas de mielina no centro da lesão até 31 dias pós-injeção de BE no tronco encefálico de ratos Wistar imunossuprimidos com $\mathrm{CY}$ e sugeriram tratar-se de uma lenta atividade macrofágica de remoção dos restos mielínicos. Os autores associaram o retardo na atividade macrofágica à ação antiinflamatória desempenhada pela $\mathrm{CY}$ ao promover prolongada monocitopenia. Bondan e col. ${ }^{22}$ observaram que, no modelo do $B E$, a supressão da função macrofágica pela CY não pareceu exercer efeito notável sobre a extensão da desmielinização e que o processo desmielinizante pareceu resultar mais da ação gliotóxica primária do agente do que de dano secundário resultante da liberação de produtos macrofágicos.

O motivo do aumento verificado em nosso estudo do número de células ED1-positivas no $14^{\circ}$ dia póslesão nos animais tratados com CY em relação aos imunocompetentes permanece desconhecido. Este fato já fora sugerido no estudo ultra-estrutural realizado por Bondan e col. ${ }^{22}$. Poderia, talvez, ser explicado por um possível atraso no recrutamento monocitário para o sítio lesional e/ou por acúmulo macrofágico decorrente da menor capacidade fagocítica exibida por tais macrófagos, conforme demonstrado por Bondan e col. ${ }^{22}$ com tal droga imunossupressora.

Na presente investigação, o padrão de resposta astrocitária verificado pela marcação imuno-histoquímica de GFAP e VIM foi semelhante ao observado nos animais imunocompetentes. Macrófagos/micróglia ativada e astrócitos reconhecidamente são capazes de influenciar-se mutuamente, estabelecendo uma comunicação bidirecional através de fatores solúveis liberados ${ }^{5}$, porém as respostas macrofágica e astrocitária podem apresentar-se também desvinculadas em sua expressão final, sob forma de diminuição da primeira com manutenção da segunda, sugerindo, assim, que outros fatores influenciem o reparo tecidual após lesão desmielinizante22.

Conclui-se, portanto, que a injeção de $10 \mu \mathrm{L}$ do gliotóxico $B E$ a $0,1 \%$ no tronco encefálico de ratos 
Wistar resultou em lesões com grande número de células ED1-positivas, havendo também a ocorrência de astrogliose, evidenciada pelo aumento da expressão de GFAP e reexpressão de VIM nos astrócitos da periferia lesional. A ciclofosfamida, por sua vez, aparentemente afetou a resposta macrofágica/microglial, conforme verificado por diferenças na quantidade de células ED1-positivas nas lesões. Já o padrão de resposta astrocitária não foi alterado com o uso da droga.

\section{REFERÊNCIAS}

1. Graça DL. Mielinização, desmielinização e remielinização no sistema nervoso central. Arq Neuro-psiquiatr 1998;46:292-297.

2. Raine CS. Morphology of myelin and myelination. Morell P (ed). Myelin. 2.ed. New York: Plenum Press, 1984:1-50.

3. Raine CS. The neuropathology of myelin diseases. Morell P (ed). Myelin. 2. ed. New York: Plenum Press, 1984:259-310.

4. Graça DL, Blakemore WF. Delayed remyelination in rat spinal cord following ethidium bromide injection. Neuropathol Appl Neurobiol 1986;12:593-605.

5. Riet-Correa G, Fernandes CG, Pereira LA, Graca DL. Ethidium bromideinduced demyelination of the sciatic nerve of adult Wistar rats. Braz J Med Biol Res 2002;35:99-104.

6. Benveniste EN. Cytokines: influence on glial cell gene expression and function. Blalack JE (ed). Neuroimmunoendocrinology. 2.ed. Basel: Karger, 1992:106-153.

7. Eng LF, Lee YL. Intermediate filaments in astrocytes. Kettenmann H, Ranson BR (eds). Neuroglia. New York: Oxford, 1995:650-666.

8. Mucke L, Oldstone MBA, Morris JC, Nerenberg MI. Rapid activation of astrocyte-specific expression of GFAP-lacZ transgene by focal injury. New Biology 1991;3:465-474.

9. Bignami A, Dahl D. Glial cells in the central nervous system and their reaction to injury. Austin: Landes, 1994.

10. Eng LR, Shiurba RA. Glial fibrillary acidic protein: a review of structure, function, and clinical application. Marangos PJ, Campbell I, Cohen RM (eds). Neuronal and glial proteins: structure, function and clinical application. New York: Academic Press, 1988:339-359.

11. Takamyia Y, Kohsaka S, Toya S, Otani, M, Tsukuda Y. Immuno-histochemical studies on the proliferation of reactive astrocytes and the expression of cytoskeletal proteins following brain injury. Dev Brain Res 1988;38:201-210.

12. Streit WJ. Microglial cells. Kettenmann H, Ranson BR (eds). Neuroglia. New York: Oxford, 1995:85-96.
13. Dijkstra CD, Dopp EA, Jolong P, Kraal G. The heterogeneity of mononuclear phagocytes in lymphoid organs: distinct MO subpopulations in the rat recognized by monoclonal antibodies ED1, ED2 and ED3. Immunology 1985;56:351-358.

14. Damoiseaux JGMC, Dopp EA, Calame W, Chao D, MacPherson GG, Dijkstra CD. Rat macrophage lysosomal membrane antigen recognized by monoclonal antibody ED1. Immunology 1994;83:140-147.

15. Wyss-Coray T, Mucke L. Inflammation in neurodegenerative disease: a double-edged sword. Neuron 2002;35:419-432.

16. Giulian D. Glia as part of the immune system. Kettenmann H, Ranson BR (eds). Neuroglia. New York: Oxford, 1995:671-684

17. Van Furth R. Phagocytic cells: development and distribution of mononuclear phagocytes in normal steady state and inflammation. Gallin JI, Goldstein IM, Snyderman R (eds). Inflammation: basic principles and clinical correlates. New York: Raven Press, 1988:281-295.

18. Van't Wout JW, Linde I, Leijh PCJ, Van Furth R. Effect of irradiation, cyclophosphamide, and etoposide (VP-16) on number of peripheral blood and peritonial leukocytes in mice under normal conditions and during acute inflammatory reaction. Inflammation 1989;3:1-14.

19. Bach JF. Immunosuppressive therapy of autoimmune diseases. Trends Pharmacol Sci 1993;14:213-216.

20. Counihan TJ, Feighery C. Immunosuppressive therapy in autoimmune disease: a review. Irish J Med Sci 1991;160:199-205.

21. Hoffman GS. Immunosuppressive therapy for autoimmune diseases. Ann Allergy 1993;70:263-270.

22. Bondan EF, Lallo MA, Sinhorini IL, Pereira LAVD, Graça DL. The effect of cyclophosphamide on brainstem remyelination following local ethidium bromide injection in Wistar rats. J Submicroscopic Cytol Pathol 2000;32:603-612.

23. Hsu SM, Raine L, Fanger H. A comparative study of the peroxidaseantiperoxidase method and an avidin-biotin complex method for studying polypeptide hormones with radioimmunoassay antibodies. Am J Clin Pathol 1981;75:734-738.

24. Fernaud-Espinosa I, Nietro-Sampedro M, Bovolenta P. Diffferential activation of microglia and astrocytes in aniso- and isomorphic gliotic tissue. Glia 1993;8:277-291.

25. Bondan EF, Lallo MA, Sinhorini IL, Baz EI, Paulino CA, Graça DL. Ultrastructural investigation on the brainstem remyelination after local ethidium bromide injection in rats immunosuppressed with dexamethasone. Acta Microscopica 1999;8:709-710.

26. Schiffer D, Giordana MT, Migheli A, Giaccone G, Pezzotta S, Mauro A. Glial fibrillary acidic protein and vimentin in experimental glial reaction of the rat brain. Brain Res 1986;374:110-118.

27. Petito CK, Morgello S, Felix JC, Lesse ML. The two patterns of reactive astrocytosis in postischemic rat brain. J Cer Blood Flow Metab 1990; 10:850-859.

28. Fujita T, Yoshimine T, Maruno M, Hayakawa T. Cellular dynamics of macrophages and microglial cells in reaction to stab wounds in rat cerebral cortex. Acta Neurochir 1998;140:275-279. 